\section{Hard Beans-A Problem for Growers, Processors, and Consumers}

\author{
D.W. Stanley
}

Additional index words. Phaseolus vulgaris, hard-to-cook defect, germination, cooking quality, bean storage, hard-shell

Summary. Hard-to-cook and hardshell are two textural defects associated with storage of legumes, as typified by the common bean. These defects can lead to failure to germinate, extended cooking times, reduced nutritional value, and economic loss throughout the food chain. Although these losses are predominate in tropical climates, beans stored in temperate areas also will harden eventually, depending on temperature and humidity. Hardened beans also often darken, causing further quality losses. Structurally, hard-shell is associated with the seedcoat and failure of water absorption, while hard-to-cook affects the cotyledons, rendering the cells unable to separate during cooking. Hardening of seedcoats during storage has been reported, and a mechanism based on oxidation and polymerization of phenolic compounds is suspected as being responsible, but few details of the hard-shell defect are known. The traditional theory used to explain the hard-to-cook defect is based on enzymatic hydrolysis of phytate, rendering it unable to chelate divalent cations that then migrate to the middle lamella and participate in crosslinking reactions with demethylated pectins. More recent evidence points to a multiple mechanism of bean hardening, with metabolism of phenolic compounds and membrane deterioration also involved. Control of bean hardening has been attempted at all levels of bean production, processing, and consumption. At present, control of storage conditions, manipulation of agronomic factors, and improved cooking techniques seem to be the best strategies to reduce bean hardening.

Department of Food Science, University of Guelph, Guelph, Ont., N1G 2W1, Canada.
$\mathrm{L}$ egumes generally, and the common bean (Phaseolus vulgaris L.) in particular, act as important sources ofprotein and other essential nutrients for most of the world's population. This results from low cost, high agronomic protein yield, and broad consumer acceptability. Beans are grown, harvested, and then stored until consumption. Drying, either in the field or by forced air in silos, to moisture levels of $\approx 10 \%$ to $20 \%$ is necessary to achieve storage stability. At this point, common beans contain $\approx 20 \%$ to $25 \%$ protein. Storage may be at the farm or at a central location. The preparation of beans by consumers involves first, a soaking step to rehydrate, and second, a cooking step to: 1) soften the plant tissue so that it is palatable, 2) inactivate heat-labile antinutrients, and 3) aid in the digestion and assimilation of protein and starch.

It is thought that all legume seeds are prone to harden during storage. For the grower this means that some seeds will not germinate and for consumers a prolonged cooking time is needed for beans to achieve suitable softness. While this latter problem may not seem serious, for those of lower socioeconomic status in developing countries where bean consumption is high and most cooking energy is provided by wood fires, hard beans can be a very real hardship. For example, it has been estimated (Hohlberg et al., 1991) that, among the lower income strata of Chile, per capita bean consumption averages $\approx 5 \mathrm{~kg}$ per person per year, and the energy cost for food cooking represents as much as $11 \%$ of total income. Of additional concern, particularly with respect to child nutrition, is the documented (Hohlberg et al., 1991) reduction of protein efficiency as cooking time is lengthened. Typical data from Chile (Hohlberg et al., 1991) indicatethat, after 10 months storage in conditions where the mean maximum temperature ranged from 14 to $31 \mathrm{C}$ and the relative humidity (RH) ranged from $63 \%$ to $93 \%$, beans approximately doubled in hardness and in cooking time, while the protein efficiency ratio decreased by $\approx 20 \%$ to considerably <1.0. In Fig. 1, comparisons are given for bean hardening ofsamples stored commercially in Chile and Canada.

Textural defects in grain legumes are not new phenomena; they were 
reported as early as the 3rd century B.C., but it is only recently that knowledge has improved to the point where the mechanisms of hardening are becoming understood, and rational strategies can be developed to counteract their effect. The purposes of this short review are to consider the importance of bean hardening to growers, processors, and consumers, with particular emphasis on the latter, and to present a summary of the work done in our laboratory on the problem. While it is not possible here reference adequately all the other research done, an attempt has been made to cite some of the key papers and reviews so that the interested reader can achieve a balanced view of this large field.

Definitions and economic importance. Two apparently distinct types ofstorage-induced textural defects have been documented in legumes. Earlier literature defined hard-to-cook (previously termed sclerema) beans as those that will not soften sufficiently because the soaked seeds do not become tender during a reasonable cooking time, while hard-shell refers to beans that fail to imbibe a sufficient quantity of water during the soaking step (Gloyer, 1921; Stanley and Aguilera, 1985). However, the distinction between these two storage-induced textural defects are

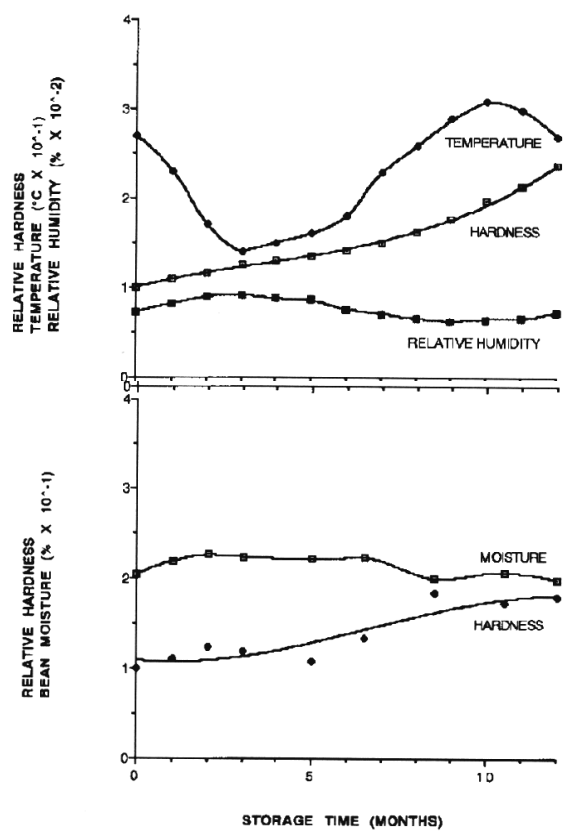

Fig. 1. Hardening data for commercially storedgray Chilean beans (top). Data taken from Hohlberg et al. (1991). Hardening data for commercially stored white Ontario beans (Bottom). Data taken from Richardson (1990). not so clear-cut and should be reconsidered in light of recent research results.

The economic importance of these two defects is easy to demonstrate but difficult to quantify. Overall losses in beans during storage result from insect and mold infestation as well as seed hardening. Specific losses due to hardening include lower prices, extra energy required for cooking, reduced nutritional value, and the cost of disposal for unacceptably hard seeds. Estimates of the seriousness of this problem are hard to obtain. In 1988, the loss of edible beans in Central America was estimated at $\$ 15$ to $\$ 16$ million (\$U.S.) per year, while in 1989 , the overall losses of only one variety of bean grown in Chile was estimated as \$4 million (\$U.S.) per year (Hohlberg et al., 1991). Of this, $<40 \%$ was attributed to physical losses and $25 \%$ to extra energy required for cooking. A study of Guatemalan farmers reported a loss of the bean crop at 32\%, 10\% of which was due to seed hardening, while the remainder was made up ofphysical and drying losses, mold, and insect attack (Stanley and Aguilera, 1985).

These losses, while not determined exactly, are not trivial. It should not be thought that northern countries escape the effects of bean hardening. Two factors, however, lessen the influence of these defects in these countries. The first is a generally temperate climate, which diminishes storage-induced hardening. The second is that the majority of the beans consumed in Canada and the United States have been thermally treated under high pressure, i.e., canned. Thermal processing can soften beans that are partially hardened and leads to a control strategy described subsequently. However, bean hardeningwill occur during storage under temperate conditions, albeit at slower rates, and this means that dry beans packed for home processing may not soften during cooking. Recent work has indicated that beans stored 1 year in commercial silos in Ontario will harden to values close to those indicative of unacceptable texture (Richardson, 1990). Thus, conditions promoting hardening exist widely and can lead to hardness, especially if bean stocks are not rotated regularly.

Symptoms and causes. Textural defects in stored beans originate in the structure of the tissue. Two of the major parts of a bean seed are the seedcoat or testa and the cotyledons. Since water absorption is at the heart of these problems, the seedcoat is of obvious concern. Structural factors that have been shown to influence water absorption significantly include seedcoat thickness, hilum size, seedvolume, and color (Agbo et al., 1987; del Valle et al., 1992a; Stanley and Aguilera, 1985). Even though the seedcoat comprises only a small $(<1 \%)$ percentage of seed volume, it contains components such as cellulose, hemicellulose, and lignin that would be expected to influence texture as well as water imbibition. A study of this aspect of bean texture indicated that both sensory and instrumental measures of bean texture were reduced by $\approx 50 \%$ when the seedcoats were removed from either soft or hard beans, thus establishing a role for seedcoats in bean texture. Of perhaps more importance was the finding that, while seedcoats soften during cooking, those from hard beans did so to a lesser degree, implying that seedcoats harden during storage (Stanley et al., 1989).

The other major constituent of beans is the paired cotyledons. Legume cotyledons are composed primarily of parenchymatous cells containing starch granules and protein bodies and bounded by a cell wall and middle lamella. These latter two structures are of importance with respect to textural defects. The composition of cell walls is qualitatively similar to seedcoats, whereas the middle lamella is characterized by the additional presence of pectic substances. Cell wall materials are estimated to make up $\approx 7 \%$ of the cotyledon by weight (Stanley and Aguilera, 1985).

Microscopic observation of cooked soft and hard beans demonstrates a major structural difference between these two tissues. Bean hardening is accompanied by a failure of the cotyledon cells to separate during cooking (Fig. 2). The conclusion from such work is that the proximate cause of bean hardness is the failure of cotyledon cells to separate during cooking. Since the middle lamella material is known to be thermally labile in the presence of sufficient moisture, the question arises whether hardening is due to a lack of water imbibition or altered middle lamella components.

The answer is probably a combination of the two. It has been reported 


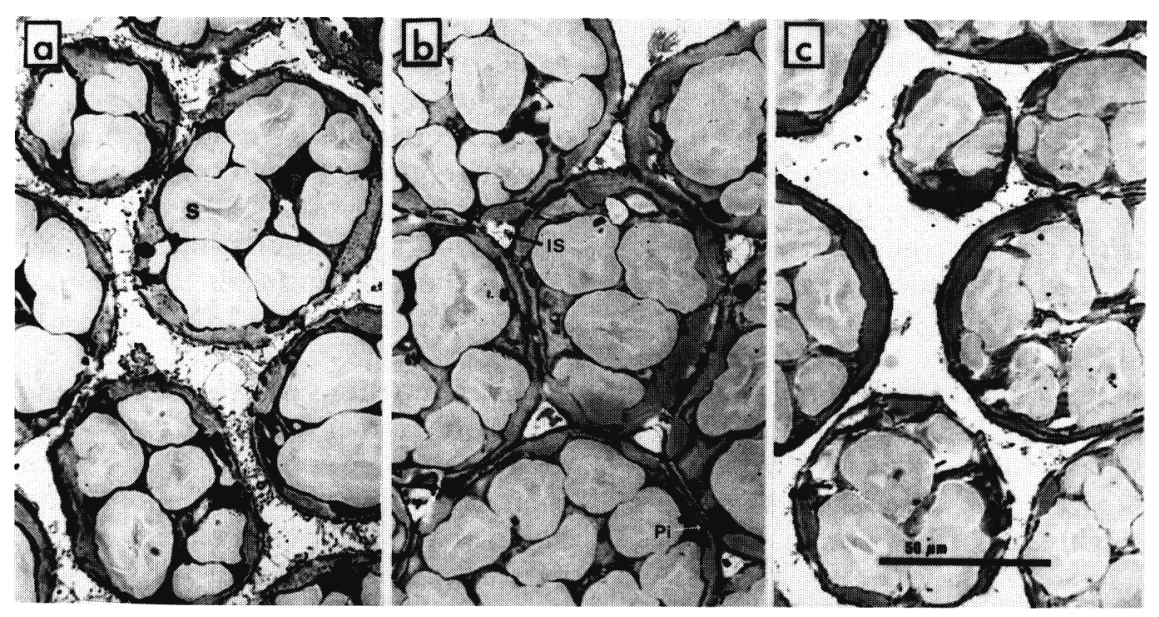

Fig. 2. Light micrographs showing bean microstructure. (a) Sample stored 8 months at 15C/35\% $\mathrm{RH}$ following $1 \mathrm{~h}$ cooking. (b) Sample stored 8 month at 30C/80\% RH following 1 h cooking (c) Sample stored 8 months at 30C/80\% RH following $3.5 \mathrm{~h}$ cooking. Note degree of cell separation. S = starch $; P=$ protein $; I S=$ intracellular space $; P i=$ pit. Source: Plhak et al. (1989), used with permission.

that hardened beans contain pectin with a lowered solubility, perhaps resulting from elevated levels of divalent cations ( $\mathrm{Ca}$ and $\mathrm{Mg}$ ) and reduced pectin esterification, meaning that more attachment sites are available for divalent cations to crosslink and insolubilize the pectins (Jones and Boulter, 1983; Stanley and Aguilera, 1985). Of at least equal importance, however, is the failure ofmoisture to penetrate the cotyledon structure. Water is a vital chemical component of several reactions necessary for bean softening. Pectin solubilization, protein denaturation, and starch gelatinization all require the presence of water, and it follows that if this reactant is limiting, softening will not occur. Earlier literature reported wide variations in water uptake of hardened beans, but this now seems to be a function of methodology. Traditional procedures led to a gross water uptake value that did not take into account bulk water that can penetrate the seedcoat but not the cotyledon cells. More refined techniques have led to the estimate that hard-to-cook beans bind $\approx 25 \%$ less water than soft beans (Plhak et al., 1989). Thus, the traditional procedure that attributed water absorption to seedcoat characteristics likely neglected to consider factors associated with the cotyledons that could also be significant.

A final symptom to be mentioned is not related to texture but has economic consequences. In light colored beans storage-induced hardening generally is accompanied by darken- ing, although all dark beans are not necessarily hard. Bean wholesalers often must reduce the price of such a product due to the implied loss of quality. The darkening reaction is catalyzed by high storage temperatures and humidities as well as artificial light, but the latter treatment does not produce hardening (Hughes and Sandsted, 1975). Investigations of the mechanism of darkening suggest that oxidation of colorless phenolic compounds results in dark polymerization products, but nonenzymatic browning is also a possibility. In Fig. 3, comparative data for darkening in red and white beans during storage is provided.

The effects ofhardening on beans intended for use as seeds should not be ignored. Laboratory storage trials showed a reduction in germination from $>90 \%$ to virtually zero following 1 year of storage at 30C and $75 \% \mathrm{RH}$ of 29 cultivars of white beans grown in Ontario (del Valle, 1992). It has been reported that for beans stored at $30 \mathrm{C}$, moisture levels exceeding $12 \%$ led to drastic ( $>90 \%$ to $<5 \%$ ) losses in germination in 16 to 24 weeks (moisture dependent) (Aguirre and Peske, 1991). These authors concluded that storage potential (germination and emergence) can be increased by a factor of 1.6 to 1.7 for every $1 \%$ reduction in moisture contentwithin the $10.5 \%$ to $14 \%$ range at 30C. This is, ofcourse, not an overly satisfying answer for small-scale tropical farmers who can rely only on the capriciousness of solar drying.

What operational factors cause beans to harden? The answer to this question is adverse storage conditions, in particular, high temperature and humidity (Aguilera and Stanley, 1985). These two factors interact to produce hardened beans if sufficient storage time has elapsed. Hardening is often a nonlinear process involving what has been termed an induction period before hardening proceeds significantly. As a rule of thumb, bean hardening becomes a hindrance to consumption when instrumentally determined hardness values double compared to the initial level. When beans are stored experimentally at a constant 30C and $75 \% \mathrm{RH}$, levels not unusual in tropical conditions, this threshold may be reached in only a few months, while noncontrolled, fluctuating field storage conditions will delay this noticeably.

A kinetic model that will predict hardness values at different storage conditions helps in the understanding of bean hardening. This has been attempted, but because of the sigmoidal shape of the hardening curve simple kinetic models do not apply. Two different models were found to fit storage data from both black and white common beans grown in Chile and Canada stored for up to 564 days under conditions that varied in moisture content from $5 \%$ to $18 \%$ and in temperature from 4 to 37C (del Valle, 1992). Coefficients of determination $\left(\mathrm{R}^{2}\right)$ varied from $96.2 \%$ to $99.7 \%$, depending on bean color, the model used, and yearto-year variations. Inputs for the models included storage time, temperature, and $\mathrm{RH}$ or moisture content. The models exhibited an initial lag period followed by a period of rapid hardening that increased with either $\mathrm{RH}$ or

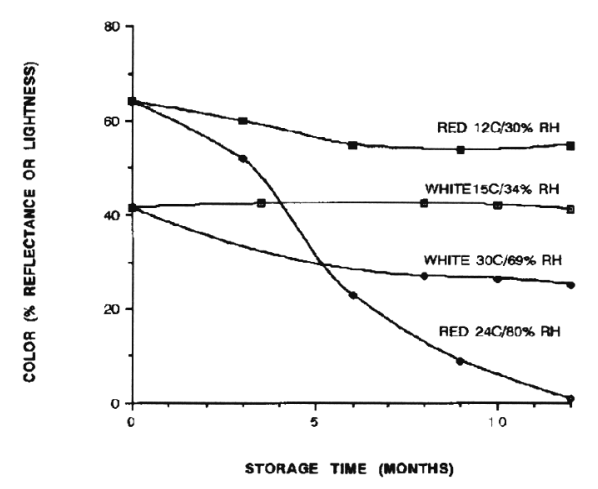

Fig. 3. Influence of storage duration and conditions on bean color. Data taken from Hughes and Sandsted (1975) and Richardson (1990). 
temperature and a final plateau region influenced only by moisture content. When using this model it is possible to make some cautious presumptions about how beans harden. Reactions showing an initial lag period typically are multistep processes requiring an initial mobilization of substrates. The shape of the hardening curve following the induction period and the activation energies determined are similar to those in which the reaction is controlled by diffusion. These reactions may be enzymatic in nature, since in solid matrices, enzymatic reactions proceed at a rate and to an extent that depends strongly on water activity (a more accepted expression of moisture level in foods), since this governs substrate mobility.

Mechanisms. In order to create effective control measures for bean hardening, it is necessary to have some idea of the biochemical mechanisms driving the hardening reaction. Empirically derived solutions often lack widespread applicability and may fail for unknown reasons. Thus, it is important to investigate the mechanisms of bean hardening.

While it is accepted that hardshell is a result of structural alterations in the seedcoat, little is known about the exact mechanism of this process (Stanley and Aguilera, 1985), although the earlier literature suggests that it is a physical condition appearing during storage in a warm but dry environment. A report of water uptake in red kidney and lima beans indicated that $\approx 50 \%$ of the samples failed to imbibe water during $24 \mathrm{~h}$ of soaking following a 5day exposure to warm but dry conditions (Gloyer, 1921). Recently, del Valle et al. (1992a) defined hard-shell as failure to swell by $>10 \%$ after $8 \mathrm{~h}$ of soaking, and an occurrence of $\approx 10 \%$ was found for common black beans stored for 1 year at $15 \mathrm{C}$ and $35 \% \mathrm{RH}$.

One concept of hard-shell takes into account the phenolic compounds found in the seedcoat that can be oxidized into complex polymers that may interact with proteins to yield a hydrophobic material that repels water imbibition (Stanley and Aguilera, 1985). The finding that darker seedcoats are less permeable to water than lighter ones tends to support this finding, since bean color is related to phenol content (Stanley et al., 1990). This brings into question the role of the hilum in water absorption. How- ever, it has been reported that cutting away an area around the hilum before soaking does not increase water uptake of hard beans (Plhak et al., 1989), whereas other literature indicates that this scarification process is effective in some cases. Thus, it is possible that a failure of the seedcoat to swell may restrict imbibition. On the other hand, beans that do not imbibe water, even when the seedcoat is totally removed (Agbo et al., 1987), must have altered cotyledons and exhibit the hard-tocook defect. Further evidence has shown that hard-shell does not occur in fresh (unstored) beans or stored beans that have been completely dehulled (del Valle et al., 1992a). A complicating factor associated with this defect is its apparent reversibility; treatments such as boiling have been reported to correct this problem (Gloyer, 1921). Semihard seeds have been defined as those capable of reversing the defect in 14 days when seed moisture was raised to $10 \%$ (Dickson and Boettger, 1982). It is apparent that more knowledge is required before hard-shell is completely understood.

The theory most frequently cited to explain the hard-to-cook defect in beans relies on observations made in the 1940 s by Sante Mattson, a Swedish scientist (Mattson, 1946). This work proposes hydrolysis of phytate, a storage form of $\mathrm{P}$ found in bean cotyledons, by the enzyme phytase (EC 3.1.3.26), which releases divalent cations previously chelated to the phytate molecule. These cations ( $\mathrm{Ca}$ and $\mathrm{Mg}$ ) then migrate to the middle lamella where they can function as crosslinking agents for the pectin molecules there. It is thought that the pectins become more reactive as a result of the action of the pectin esterase enzyme, which demethylates the molecule, leaving a carboxyl group that can enter into crosslinking reactions. Crosslinked pectins in the middle lamella do not solubilize during cooking, leading to unseparated cells and tough beans (Jones and Boulter, 1983; Stanley and Aguilera, 1985).

This mechanism is employed usefully by food scientists when Ca salts are added to products such as canned tomatoes and potatoes to prevent cell sloughing during processing. High temperatures and humidities encountered during storage of beans under tropical conditions may potentiate endogenous enzymes, perhaps as a prelude to germination. Both of these conditions are needed for this defect to occur. Soft beans have intact phytate molecules capable ofchelating divalent cations from the middle lamella, leaving monovalent cations ( $\mathrm{Na}$ and $\mathrm{K}$ ) to interact with pectins, and leading to a structure that is heat-labile (Stanley and Aguilera, 1985).

This hypothesis has been used widely to explain bean hardening, yet other more recent data suggest several other mechanisms that may assert themselves during this process. Indeed, a complex phenomenon such as bean hardening being governed by a single mechanism seems unlikely.

Two alternative but probably not independent mechanisms for bean hardening will now be presented, both of which seem to play a role in the hard-to-cook defect. One will see again that a true scientific discovery or breakthrough, especially in the biological area, is rare indeed. Scientists build on the work of others, often not directly in their field of interest, to make small but important contributions that lead in the fullness of time to a more complete understanding of the process being studied. Postulating a role for phenolic compounds in bean hardening has followed this path, in that E.C. Bate-Smith, a well-respected British meat scientist who only became interested in phenolic compounds later in his career, made a connection between phenolic substances and textural quality in beans (Bate-Smith, 1958). He demonstrated that the deposition of leucoanthocyanins in the form of condensed tannins occurs in conjunction with lignin to incrust and toughen cell walls (BateSmith, 1958; Stanley, 1992). Even now little is known about the chemical reactions involved in the condensation of monomeric phenols, but the structure of these large polymers is thought to be as complex as that of lignin. The biological function of tannins is related to their ability to repel animal and microbial predators, depending on the combined properties of astringency and protein precipitation. On a grander scale, it has been suggested that as life evolved on this planet a shift occurred from a predominantly $\mathrm{CO}_{2}$ atmosphere, suitable for anaerobic microorganisms and plants, to one high in oxygen, a powerful toxin to these species. Plant phenolics might have 
evolved as an antioxidant, since they can react with hydroxyl to produce lignin, a stable C-containing polymer that resists biodegradation (Lovelock, 1990).

Is there a role for this reaction in bean hardening? In Fig. 4, work is depicted in which red kidney beans were stored under adverse conditions, and the total soluble condensed tannins of the seedcoat were measured along with bean hardness. A highly significant, negative correlation was found between these two variables. As the beans hardened, smaller amounts of soluble tannins were extracted (Rozo, 1982). One may infer from these data that the decline in soluble tannins represented an increase in condensed tannins in the seedcoat and perhaps a migration of soluble tannins to the cotyledon. Tannins are found in both the seedcoat and cotyledon, and, in general, the ratio of seedcoat to cotyledon tannin content in beans is $\approx 80: 20$ (Stanley, 1992). At this point it would be tempting to speculate that the deposition ofcondensed tannins in the seedcoat, rather than repelling water, restricts swelling of the seedcoat and leads to hard-shell, whereas a similar reaction in cotyledon cells strengthens this tissue and contributes to hardness. Obviously, further proof will be required to corroborate this theory.

Several lines of evidence have come together to furnish support for the concept of phenol condensation as a viable component of bean hardening. These are summarized as follows:

ž Electron micrographs of cell wall material isolated from hard beans showed that depositions of material reacting to a lignin stain was heavier than similar material isolated from soft

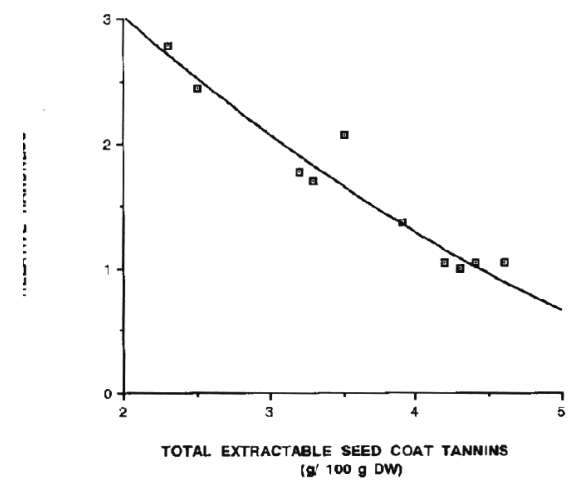

Fig. 4. Relationship of seedcoat tannins to bean hardening in red kidney beans. Data taken from Rozo (1982). beans (Hincks and Stanley, 1987).

ž Cell walls, treated to extract tannins, revealed significantly more tan nins in hard than soft bean samples (Stanley, 1992).

ž Chemical analysis of bean extracts indicated that tropical storage conditions reduced the concentration of extractable tannins and that the unextractable material migrated from the seedcoat to the cotyledons (Stanley, 1992). These results substantiate earlier visual observations that cotyledons of soaked beans with dark seedcoats blacken with hardening and that the soaking solution is less colored than that used to soak comparable soft beans (Hincks et al., 1987).

ž Even though white beans sampled in the above work contained low concentrations of tannins, significant hardening occurs in these cultivars. Another possibility for phenol formation may be the demonstrated enzymatic hydrolysis of storage proteins during tropical storage, with a resulting build-up of aromatic amino acids (Hohlberg and Stanley, 1987). These can enter the shikimate pathway, a major source of phenol biosynthesis. Also, tropical storage may induce stress that initiates phenol production. Other analytical work has shown significant changes in the content of both seedcoat and cotyledon phenolic acids as a result of elevated storage conditions (Srisuma et al., 1989).

Ž A rapid method was developed to assay for total in situ seed phenolics using fluorescence microscopy (Stanley and Plhak, 1989). Results of this test were found to correlate significantly with hardness of many different bean samples as well as with isolated cell wall material.

ž The mechanism by which phenols condense are thought to be both enzymatic and nonenzymatic in nature. The enzymatic route is thought to be catalyzed by peroxidase (EC 1.11.1.7) that oxidatively couples subunits. This enzyme was studied during bean hardening, and it was found that peroxidase-specific activity increased initially in beans stored under tropical conditions but later the activity decreased, perhaps due to inactivation or binding (Plhak et al., 1987; Rivera et al., 1989). It is quite likely that in situ peroxidase activity is appreciably higher in tropically stored beans.

ž Finally, the kinetic study men- tioned previously further established that hardening rates increased with either water activity or storage temperature, whereas the extent of the reaction was dictated only by water activity (del Valle, 1992). This suggested a multiple mechanism of hardening and substantiated an earlier concept based on phenol and phytate analyses (Hincks and Stanley, 1986).

Taken together, this research supports the concept of a multiple mechanism of bean hardening based on both phytate- and phenol-based reactions. A recent experiment was designed to test this hypothesis using methodology aimed at discriminating physically and chemically between the two components (del Valle, 1992). Chemical tests included phytate analysis and fluorescence microscopy, while hardening was divided into reversible and nonreversible portions by soaking beans in a solution of EDTA before cooking. This step removed divalent cations from hard-to-cook beans and replaced them with $\mathrm{Na}$ to counteract the hardening effect of the pectinphytate mechanism, leaving only the hardness due to phenols and condensed tannins. Samples studiedincluded black and white beans, hulled or dehulled, soaked in water or EDTA solution. These were kept at three different relative humidities at each of three temperatures, and samples were taken at various time intervals for chemical and physical testing. Total hardness (puncture force of cooked beans previously soaked in water) minus irreversible hardness (puncture force of cooked beans previously soaked in EDTA) was defined as reversible hardness (Aguilera and Rivera, 1992). Both components of hardening increased during storage, as indicated in Fig. 5. The chemical data strongly suggest that reversible hardening is associated with phytate metabolism, whereas irreversible hardening is more related to metabolism of phenolic compounds. Dehulled beans had lost their seedcoat tannins, so they exhibited reduced irreversible hardness; however, a degree of irreversible hardness occurred in white beans, suggesting that seedcoat tannins are not the sole source of substrate for this component. It was noted further that the rate of the irreversible reaction was more temperature dependent than the reversible reaction.

The other possible mechanism important in bean hardness is membrane deterioration. Biological mem- 


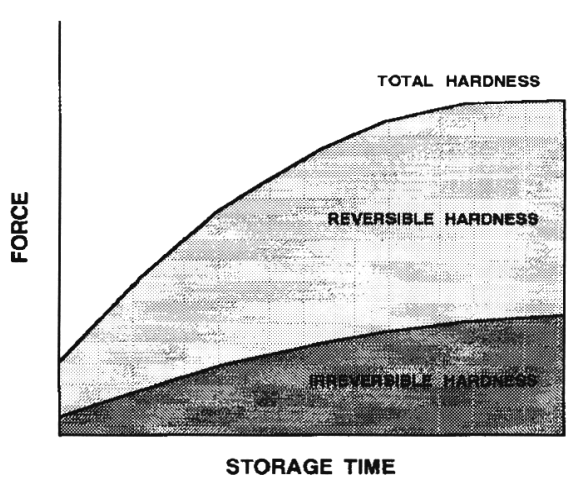

Fig. 5. Representation of bean hardening as a result of reversible and irreversible components. Data taken from Stanley and del Valle, 1991.

branes serve roles such as keeping solutes inside the cell and separating enzymes from potential substrates. These functions are impaired if membranes lose their critical permeability (Stanley, 1991). Beans stored under adverse conditions exhibit increased loss of solids and electrolyte leakage during soaking as compared to those treated more mildly, which suggests membrane disruption (Richardson and Stanley, 1991; Stanley and Aguilera, 1985). One way of determining membrane functionality is to measure the phase transition temperature, a parameter inversely related to membrane fluidity. Fluidity, in turn, decreases in senescing tissues and correlates with loss of biological integrity. When membranes from beans stored under a wide variety of conditions were examined, a high correlation was found between both hardness and solids lost during soaking and the membrane phase transition temperature (Fig. 6). A generalized scheme for membrane deterioration entails membrane phospholipids undergoing hydrolysis to free fatty acids through the action of phospholipases. Free fatty acids then are attacked by lipoxygenase (EC 1.13.11.12), which generates free radicals as well as oxidized lipids. Free radicals act as destabilizing agents, altering fluidity and leading to dysfuntional membranes characterized by loss of permeability and eventually leading to deterioration of tissue quality (Stanley, 1991). The finding that measurable membrane deterioration in beans is closely related to subsequent textural defects is of importance, since this could prove to be the primary event in hardening, as it has been shown in other plant tissue systems.
Although the exact contribution of each mechanism to total bean hardness is not yet known, some understanding of the cause oftextural defects in legumes has been achieved. There is compelling evidence that more than one mechanism is involved in the storage-induced textural defect problem. In this case, progress consists of a simplified view being replaced with the understanding that hardening is a result of a highly complex interrelated group of multiple mechanisms, the dominance of which is controlled by complicated genetic and environmental interactions. Traditionally, bean hardening defects have been classified as either hard-shell or hard-to-cook, depending on the tissue affected. As more becomes known about the mechanisms responsible for these reactions, it appears they may be more closely related than previously thought, since phenol oxidation is suggested to operate in both cases (Table 1). It seems clear that enzymes are involved in bean hardening. Thus far, the following six have been mentioned: lipoxygenase, pectin esterase, peroxidase, phospholipases, phytase, and proteases. Their control will be discussed in the following section, although, as will be shown, a nonenzymic component of hardening can not be ruled out.

Control strategies. The accumulated scientific knowledge gained thus far concerning bean hardening is of little use unless it can be directed toward alleviating this problem. Although research in this area leaves unanswered questions, some methods have been found that might prove fruitful in ameliorating bean seed hardening.

ž Genetic control. If hardening could be controlled successfully by breeding programs, new cultivars could be developed that remain easy to cook even after prolonged storage under adverse conditions. Although hardshell seems to be amenable to plant breeding (Dickson and Boettger, 1982; Stanley and Aguilera, 1985), the hardto-cook defect showed low heritability (0 to 0.24$)$ with high standard errors, whereas high (0.29 to 0.69$)$ phenotypic variance due to genetic $\times$ environmental interaction was found (Michaels and Stanley, 1991). Nevertheless, claims have been made that cooking time can be changed through selection (Shellie-Desser and Hosfield, 1991;
Wassimi et al., 1990), and the use of faster-cooking cultivars before storage-induced defects may save scarce fuel supplies.

žAgronomic control. Significant differences exist among bean cultivars with respect to hardening potential, but all beans may harden under adverse storage conditions. Also, environmental factors such as soil conditions, temperature, and moisture stresses are important, suggesting that the hardto-cook defect is at least partially a physiological response of seeds to environmental stresses. Factors found to be of the highest significance in cooked hardness of stored beans during a study of 29 white bean cultivars grown at six locations in Ontario included, in order of importance, soil $\mathrm{pH}$, average temperature from planting to $50 \%$ blossom, $\mathrm{P}$ content of the soil, total precipitation from $50 \%$ blossom to maturity, and $\mathrm{Mg}$ content of the soil (del Valle, 1992). Earlier pot experiments in which peas were grown with various levels of added phosphates resulted in a strong positive correlation among phosphate levels, bean phytate levels, and softness of cooked beans, irrespective of other added monovalent or divalent cations (Mattson et al., 1950). A strategy based on managing environmental factors may prove worthwhile, especially since in tropical areas where this problem predominates the ability to improve storage conditions is limited. Accumulated knowledge of the hard-tocook defect has led to the axiom that the best cure is prevention. Optimizing soil $\mathrm{pH}$ could be a starting point for a preventative program aimed at agronomic control.

ž Processing control. Clearly the most obvious way to deter hardness is

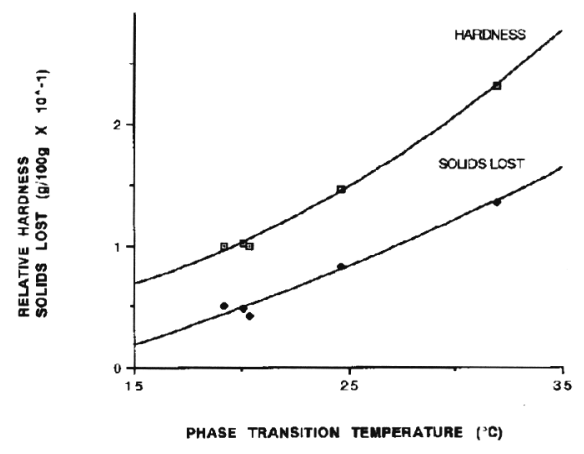

Fig. 6. Relationship of membrane breakdown, measured as increasing phase transition temperature, with bean hardness and solids lost during soaking. Data taken from Richardson and Stanley (1991). 
Table 1. Possible relationships between reversible and irreversible hardness in beans.

\begin{tabular}{|c|c|c|}
\hline Parameter & Reversible & Irreversible \\
\hline Defect induced & Hard to cook & $\begin{array}{l}\text { Hard-shell (testa) } \\
\text { Hard-to-cook (cotyledon) }\end{array}$ \\
\hline Substate & Phytate and pectates & Monomeric phenols \\
\hline Storage variables & Water activity and temperature & $\begin{array}{l}\text { Temperature only in testa } \\
\text { Both in cotyledon }\end{array}$ \\
\hline Major influence & Extent of hardening & Hardening rate \\
\hline Control & Diffusion-controlled & $\begin{array}{l}\text { Diffusion-independent (testa) } \\
\text { Diffusion-controlled (cotyledon) }\end{array}$ \\
\hline
\end{tabular}

to store beans in conditions of low temperature and humidity for as short a time as possible. That this is not practiced speaks more to the inverse relationship between geographic distribution and severity of the problem with the technological and financial ability to control it than to a lack of scientific knowledge of how to proceed. Temperature and humidity control are expensive for developing countries, and beans need to be stored from one growing season to the next. Some unique attempts to solving bean hardening include buried storages, submerged storages in rivers or lakes, and inexpensive storage materials such as plastic bags. None of these are totally satisfactory, however, and the search continues for low-cost but effective procedures.

Heating is a common approach to inactivate unwanted enzymes in food, and this has been investigated as a process to control bean hardening (Molina et al., 1976). One approach to heating beans has been dry roasting in hot sand. This reduces moisture levels, inactivates enzymes, and also serves to disinfect beans. However, other unwanted side effects also appear, including a tendency to reabsorb moisture if not packaged promptly and correctly, case hardening in which subsequent water imbibition is deterred, and continued, though diminished, hardening during storage (Aguilera and Stanley, 1985). The latter observation suggests a nonenzymatic route for hardening, and nonenzymatic polymerization of phenolic compounds has been reported to proceed by way of a free-radical mechanism (Smith and Stanley, 1989). Other attempts at preventing hardening during storage by using processes including irradiation and extrusion, or milling of hard beans, remain beyond the ability of most developing countries as well as yielding unfamiliar products that lack acceptability by bean consumers (Aguilera and Stanley, 1985).

A novel application of scientific principals to bean hardening was the development by Rockland and others of "quick cooking" beans in which a solution ofmonovalent phosphate and other salts are vacuum-infiltrated into beans that then can be redried. This protocol is claimed to reduce cooking time by $\geq 80 \%$ and is thought to rely on replacing divalent cations in pectates with monovalent ions, leading to cell separation during cooking (Aguilera and Stanley, 1985; Rockland and Metzler, 1967). This process does not seem to be commercially feasible at present, perhaps due to associated flavor problems.

As noted before, bean hardening is also a potential problem in temperate production areas. Control of hardening is much easier in these climates compared to tropical areas. Wholesalers and processors need to ensure that older stocks are used completely before newly harvested beans are added, while at the retail level rotation of packages is necessary. A date-coding system used throughout the commercial chain would be an effective control measure. Hohlberb et al. (1991). beans soaked and canned using a commercial process. ž Consumer control. Consumers are the last link in the food chain. Control mechanisms available to this group include cooking procedures and cooking additives. These, coupledwith a strong need for nutritional adequacy, have led to several examples of improved bean use. Shellie-Dessert and Hosfield (1990) have reported a successful "crock pot" procedure capable of reducing wood consumption by $\approx 40 \%$ during trials in Rwanda. Chilean researchers estimated the cost of different bean preparation procedures (Hohlberg et al., 1991). Canning provides soft beans a prolonged, ambient temperature and shelf stability. The cost, however, is over twice that of any other procedure (Table 2). Eliminating the soaking step may save time but it adds to the total cost. Pressure-cooking offers a significant cost savings, but the price of the pressure cooker is also a factor. Quick cooking and soaking in salt solutions both provide a large savings; however, the consumption of salts (4.5 g per $100 \mathrm{ml}$ soaking solution) raises both sensory and health questions.

The use of salts by consumers in bean soaking or cooking solutions seems to be a widespread practice. Adding a liberal "pinch" of sodium bicarbonate or sodium carbonate is even called for in some recipes. As mentioned previously, it has been thought that the effectiveness of chelating and ion exchange agents in bean preparation is due to the improved solubilization of pectates in the middle lamella during cooking. Newer information suggests that this softening effect is not achieved by reduced cell attachment alone and that reduced protein denaturation temperature also contributes significantly to this pro-

Table 2. Cost per tonne of different bean preparation procedures in Chile. Data taken from

\begin{tabular}{lccccrr}
\hline Factor & Control & Unsoaked & $\begin{array}{c}\text { Pressure } \\
\text { cooking }\end{array}$ & $\begin{array}{c}\text { Salt } \\
\text { soaking }\end{array}$ & $\begin{array}{c}\text { Quick } \\
\text { cooking }\end{array}$ & Canning \\
\hline Pretreatment cost ${ }^{2}$ (\$U.S.) & 0 & 0 & 96 & 84 & 136 & 960 \\
Cooking time (min) & 180 & 200 & 60 & 28 & 35 & 5 \\
Gas consumption (liters) & 174 & 195 & 54 & 26 & 33 & 4 \\
Energy cost & 352 & 392 & 118 & 52 & 66 & 6 \\
Total cost & 352 & 392 & 214 & 136 & 202 & 966
\end{tabular}

Pretreatments: Control, beanssoaked overnight in tap water and cooked in an open pot over a gas flame; Unsoaked, as in control, but beans notsoaked; Pressure cooking soaked beans cooked in a pressure cooker over a gas flame; Salt soaking beanssoaked overnight in an aqueous solution of sodium salts and cooked in an open pot over a gas flame; Quick cooking beanssoaked overnight in an aqueous solution of sodium salts, rinsed in tap water, dried with forced air, and cooked in an open pot over a gas flame; Canning 
cess (del Valle et al., 1992a; GarciaVela et al., 1991). Kinetic analysis indicated that the softening rate of hardened samples was slower than the solubilization rate of pectic substances; suggesting that other components contribute to reduced cell separation and indirectly supporting the previous hypothesis of multiple mechanisms in bean hardening (Fig. 7).

The data provided in this review support the following conclusions:

ž Hardening is a real problem for bean growers, processors, and consumers and can cause significant economic losses. The extent of the problem is a function of ambient storage conditions and technological ability to retard hardening, so that developing countries experience a greater incidence than others. However, even in temperate zones bean hardening can be worrisome if ignored.

ž Seedcoats, cotyledons, or both can harden if conditions are suitable. Hardened beans are characterized by lowered water imbibition, longer cooking times, discoloration, and reduced germination levels. Elevated storage temperature and humidity and their duration increase the extent of hardening.

ž Progress has been made in studies of the biochemical mechanisms of hardening. A multiple mechanism in-

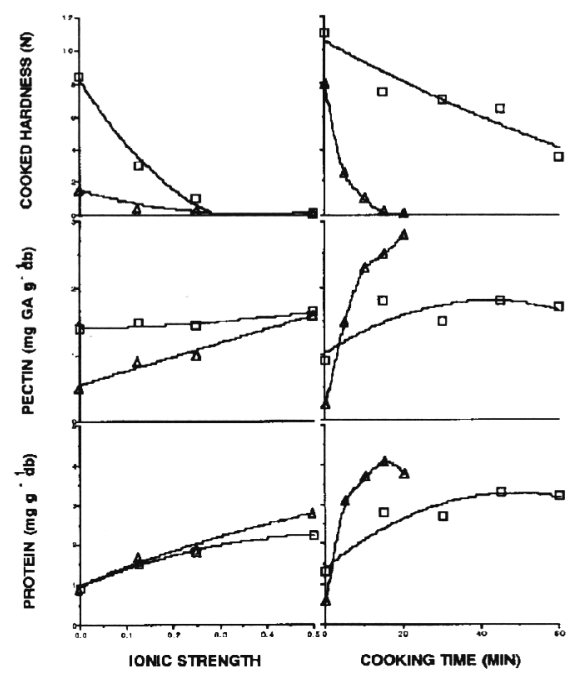

Fig. 7. (Left) Cooked hardness, solubilized pectin, and solubilized protein levels following soaking black beans $18 \mathrm{~h}$ in $\mathrm{pH} 10$ carbonate buffer as a function of ionic strength. (Right) Cooked hardness, leached pectin, and solubilized protein levels following soaking black bean $18 \mathrm{~h}$ in water as a function of cooking time. $\Delta-\Delta-\Delta=$ soft beans, $\square-\square-\square=$ hard beans. Data taken from del Valle et al. (1992b). volving several pathways is evident.

ž While genetic intervention does not seem promising at this time, not enough work has been done in screening the vast array of Phaseolus accessions to conclude that this approach may not be useful in the future. Producers may be able to manipulate agronomic factors to their benefit. Processors can overcome hardening completely by canning, a procedure that also can be achieved in the home through pressure cooking. Some softening can be attained during cooking by the addition ofvarious salts during soaking or cooking.

\section{Literature Cited}

Agbo, G. N., G.L. Hosfield, M.A. Uebersax, and K. Klomparens. 1987. Seed microstructure and its relationship to water uptake in isogenic lines and a cultivar of dry beans (Phaseolus vulgaris L.). Food Microstructure 6:91-102.

Aguilera, J.M. and J.A. Rivera. 1992. Hardto-cook defect in black beans: Hardening rates, water imbibition and multiple mechanism hypothesis. Food Res. Intl. 25:101-108.

Aguilera, J.M. and D. W. Stanley. 1985. A review of textural defects in cooked reconstituted legumes. The influence of storage and processing. J. Food Process. Preserv. 9:145-169.

Aguirre, R. and S.T. Peske. 1991. Seed moisture content required for short-term hermetic storage of beans. Seed Sci. Technol. 19:117-122.

Bate-Smith, E.C. 1958. The contribution of phenolic substances to quality in plant products. Qualitas Plant. 34:440-455.

del Valle, J.M. 1992. Studies on the hardto-cook defect of beans (Phaseolus vulgaris L.). PhD Diss., Univ. of Guelph, Guelph, Ont., Canada.

del Valle, J.M., T.J. Cottrell, R.L. Jackman, and D. W. Stanley. 1992a. The hard-to-cook defect in black beans. Protein effects of salt soaking. Food Sci. Intl. (In press.)

del Valle, J.M., D. W. Stanley, and M.C. Bourne. 1992b. Water absorption and swelling in dry bean seeds. J. Food Process. Preserv. 16:75-98.

Dickson, M.H. and M.A. Boettger. 1982. Heritability of semi-hard seed induced by low seed moisture in beans (Phaseolus vulgaris L.). J. Amer. Soc. Hort. Sci. 107:69-71.

Garcia-Vela, L.A., J.M. del Valle, and D. W. Stanley. 1991. Hard-to-cook defect in black beans: The effect of soaking in various aqueous salt solutions. Can. Inst. Food Sci. Technol. J. 24:60-67.

Gloyer, W.O. 1921. Sclerema and hardshell, two types of hardness of the bean. Proc. Amer. Assn. Official Seed Anal. 13:60.

Hincks, M.J., A. McCannel, and D.W. Stanley. 1987. Hard- to-cook defect in black beans. Soaking and cooking processes. J. Agr. Food Chem. 35:576-583.

Hincks, J.M. and D. W. Stanley. 1986. Multiple mechanisms of bean hardening. J. Food Technol. 21:731-750.

Hincks, M.J. and D. W. Stanley. 1987. Lignification: Evidence for a role in hardto-cook beans. J. Food Biochem. 11:4158.

Hohlberg, A. I., J.M. Aguilera, and R. Diaz. 1991. Economic evaluation of postharvest losses and utilization of hardened beans: A case study in Chile. Ecol. Food Nutr. 25:275-286.

Hohlberg, A.I. and D. W. Stanley. 1987. Hard-to-cook defect in black beans. Protein and starch consideration. J. Agr. Food Chem. 35:571-576.

Hughes, P.A. and R.F. Sandsted. 1975. Effect of temperature, relative humidity, and light on the color of 'California Light Red Kidney' bean seed during storage. HortScience 10:421-423.

Jones, P.M.B. and D. Boulter. 1983. The cause of reduced cooking rate in Phaseolus vulgaris following adverse storage conditions. J. Food Sci. 48:623-626,649.

Lovelock, J. 1990. The ages of Gaia. Bantam, New York.

Mattson, S. 1946. The cookability of yellow peas: A colloid-chemical and biochemical study. Acta Agr. Suecana II 2:185-231.

Mattson, S., E. Akerberg, E. Eriksson, E. Koutler-Andersson, and K. Vahtras. 1950. Factors determining the composition and cookability of peas. Acta Agr. Scand. 1:4061.

Michaels, T.E. and D. W. Stanley. 1991. Stability and inheritance ofstorage-induced hardening in 20 common bean cultivars. Can. J. Plant Sci. 71:641-647.

Molina, M.R., M.A. Bater, R.A. GomezBrenes, K. W. King, and R. Bressani. 1976. Heat treatment: A process to control the development of the hard-to-cook phenomenon in black beans (Phaseolus vulgaris). J. Food Sci. 41:661-666.

Plhak, L.C., K.B. Caldwell, and D.W. Stanley. 1989. Comparison ofmethods used to characterize water imbibition in hardto-cook beans. J. Food Sci. 54:326-329, 336. 
Plhak, L.C., D. W. Stanley, A.I. Hohlberg, and J.M. Aguilera. 1987. Hard-to-cook defect in black beans-effect of pretreatment and storage condition on extractable phenols and peroxidase activity. Can. Inst. Food Sci. Technol. J. 20:378-382.

Richardson, J. C. 1990. Mathematical and physicalinvestigations of the 'hard-to-cook defect in Ontario white beans (Phaseolus vulgaris cv. OAC Rico). MS Thesis, Univ. of Guelph, Guelph, Ont., Canada.

Richardson, J. C. and D. W. Stanley. 1991. Relationship of loss of membrane functionality and hard-to-cook defect in aged beans. J. Food Sci. 56:590-591.

Rivera, J.A., A.I. Hohlberg, J.M. Aguilera, L.C. Plhak, and D. W. Stanley. 1989. Hardto-cook defect in black beans. Peroxidase characterization and effect of heat pretreatment and storage conditions on enzyme inactivation. Can. Inst. Food Sci. Technol. J. 22:270-275.

Rockland, L.B. and E.A. Metzler. 1967. Quick-cooking and other dry beans. Food Technol. 21:344-348.

Rozo, C. 1982. Effect of extended storage on the degree of thermal softening during cooking, cell wall components, and polyphenolic compounds of red kidney beans (Phaseolus vulgaris). PhD Diss., Cornell Univ., Ithica, N.Y.

Shellie-Dessert, K.C. and G.L. Hosfield. 1990. Implications of genetic variability for dry bean cooking time and novel cooking methods for fuelwood conservation in Rwanda. Ecol. Food Nutr. 24:195-211.

Smith, J.L. and D.W. Stanley. 1989. Toughening in blanched asparagus: Identification of phenolic compounds and evidence for a free radical mechanism. J. Food Biochem. 13:271-287.

Srisuma, N., R. Hammerschmidt, M.A. Uebersax, S. Ruengsakulrach, M.R. Bennink, and G.L. Hosfield. 1989. Storage induced changes of phenolic acids and the development of hard-to-cook in dry beans
(Phaseolus vulgaris, var. Seafarer). J. Food Sci. 54:311-314, 318.

Stanley, D. W. 1991. Biological membrane deterioration and associated quality losses in food tissues. Crit. Rev. Food Sci. Nutr. 30:487-553.

Stanley, D. W. 1992. A possible role for condensed tannins in bean hardening. Food Sci. Intl. (In press.)

Stanley, D. W. and J.M. Aguilera. 1985. A review of textural defects in cooked reconstituted legumes. The influence of structure and composition. J. Food Biochem. 9:277-323.

Stanley, D. W. and J.M. del Valle. 1991. Chemical approaches to the utilization of hard-to-cook beans. Presented at 8th World Congr. Food Sci. Technol., Toronto.

Stanley, D. W. and L.C. Plhak. 1989. Fluorescence intensity indicates bean hardening. J. Food Sci. 54:1076-1077.

Stanley, D. W., T.E. Michaels, L.C. Plhak, and K.B. Caldwell. 1990. Storage-induced hardening in 20 common bean cultivars. J. Food Quality 13:233-247.

Stanley, D. W., X. Wu, and L.C. Plhak. 1989. Seedcoat effects in cooked reconstituted bean texture. J. Texture Studies 20:419-429.

Wassimi, N.N., G.L. Hosfield, and M.A. Uebersax. 1990. Inheritance of physicochemical seed characters related to culinary quality in dry bean. J. Amer Soc. Hort. Sci. 115:492-499.

\section{Acknowledgements}

Work from this laboratory has been supported by the Natural Sciences and Engineering Research Council of Canada, the International Development Research Centre of Canada, the Ontario Bean Producers' Marketing Board, and the Ontario Ministry of Agriculture and Food. 